\title{
Refractory Ph-Like Acute Lymphoblastic Leukemia
}

National Cancer Institute

\section{Source}

National Cancer Institute. Refractory Ph-Like Acute Lymphoblastic Leukemia. NCI

Thesaurus. Code C134835.

Ph-like acute lymphoblastic leukemia that does not respond to treatment. 